\title{
MELHORIA DA QUALIDADE DO DIMENSIONAL DAS BARRAS REDONDAS LAMINADAS NO LCP NA VOTORANTIM SIDERURGIA*
}

\section{Resumo}

Izabelle Lannes Salgueiro Ferreira ${ }^{1}$ Taciana Rezende Pereira ${ }^{2}$ Edson Vasconcelos ${ }^{3}$

Bruner Cândido Siqueira ${ }^{4}$ Renato de Carvalho Vieira ${ }^{5}$ Leandro Carlos Pinto de Almeida ${ }^{5}$

O presente trabalho teve como objetivo garantir a estabilidade no processo de conformação mecânica das barras redondas laminadas, visando reduzir a geração de produtos não conformes e o número de reclamações de clientes pelo motivo de ovalização. As barras redondas laminadas são utilizadas nas indústrias de trefilação, metal mecânico, agroindústria e em outros componentes industriais. A metodologia utilizada neste trabalho foi DMAIC, (definir, medir, analisar, melhorar e controlar). Esta ferramenta é utilizada para melhoria de processos. Através desta ferramenta foi possível identificar os parâmetros mais influentes na geração de defeitos por ovalização, o que possibilitou a elaboração de um plano de ação direcionado às causas raízes. Após a conclusão do plano de ação, houve redução de $36 \%$ em média na geração de produtos não conformes e nenhuma reclamação de cliente foi recebida até o mês de março de 2016, além de uma maior estabilidade do processo durante a laminação deste produto.

Palavras-chave: Laminação a quente; Barras redondas laminadas; DMAIC; Ovalização.

\section{QUALITY IMPROVEMENT OF THE DIMENSIONAL OF ROUND BARS HOT ROLLED IN LCP IN VOTORANTIM SIDERURGIA}

\section{Abstract}

This study aimed to ensure stability in the hot rolling process of round bars with the purpose to reduce the generation of products with defects and the number of customer complaints by out-of-roundness round bars. The hot rolled round bars are used in drawing industries, mechanical metal, agro-industry and other industrial components. The methodology used was DMAIC (define, measure, analyze, improve and control). This tool is used to improve processes. By the use of this tool was possible to identify the most influential parameters in the generation of out-of-roundness round bars, which enabled the development of an action plan directed to the root causes. After the end of the action plan, there was a reduction of $36 \%$ in the generation of defective products and no customer complaint was received until march of 2016, in addition to a greater stability during the hot rolling process of this product.

Keywords: Hot rolling; Round bars; DMAIC; Out-of-roundness.

1 Engenharia Metalúrgica UFF, Engenheira de Processo, Gerencia de Laminação a Quente, Votorantim Siderurgia, Barra Mansa, Rio de Janeiro, Brasil.

2 Engenheira Metalurgista UFMG, Mestranda em Engenharia de Materiais EEL USP, Engenheira de Produto, Votorantim Siderurgia, Resende, Rio de Janeiro, Brasil.

3 Engenharia Civil FOA, Especialista de Processo, Gerencia de Laminação a Quente, Votorantim Siderurgia, Barra Mansa, Rio de Janeiro, Brasil.

4 Engenharia de Produção UBM, Técnico Especialista em Oficina, Votorantim Siderurgia, Barra Mansa, Rio de Janeiro, Brasil.

5 Técnico Mecânica, SENAI, Técnico Especialista em Oficina, Votorantim Siderurgia, Barra Mansa, Rio de Janeiro, Brasil. 


\section{INTRODUÇÃO}

No Brasil, as principais razões para a utilização de barras redondas laminadas são nas indústrias de trefilação, metal mecânico, agroindústria e em outros componentes industriais. Visando atender este atraente mercado, com alta margem de contribuição, a Votorantim Siderurgia definiu como projeto estratégico a melhoria da qualidade dimensional destes produtos.

A barra redonda laminada é fabricada no Laminador Contínuo de Perfis (LCP) localizado na Unidade de Barra Mansa. O LCP é um laminador a quente, contínuo, com um número ímpar de gaiolas (17 gaiolas), dotado de gaiolas horizontais e verticais. Este equipamento foi projetado para fabricação de vigas $\mathrm{U}$ e I, cantoneiras, barra redonda laminada, barra chata e vergalhão.

A faixa das bitolas de barra redonda produzidas no LCP abrange as bitolas de 5/8" até 3" e os aços utilizados são ASTM 1012, 1020 e 1045. A norma de referência utilizada neste trabalho para fabricação de barras redondas laminadas foi a NBR 13283.

O presente trabalho teve como objetivo garantir a estabilidade no processo de conformação mecânica das barras redondas laminadas, visando reduzir a geração de produtos não conformes e o número de reclamações de clientes pelo motivo de ovalização.

A metodologia utilizada foi o DMAIC, (definir, medir, analisar, melhorar e controlar). Esta ferramenta é utilizada para melhoria de processos, através dela foi possível identificar as principais variáveis de processo na geração de defeitos por ovalização, o que possibilitou a elaboração de um plano de ação direcionado às variáveis críticas. Após a conclusão do plano de ação, foi possível evidenciar uma redução de em média 36 \% na geração de produtos não conformes, nenhuma reclamação de cliente foi recebida até o mês de Março de 2016 e estabilidade do processo durante a laminação deste produto.

\section{MATERIAIS E MÉTODOS}

Devido aos inúmeros problemas com reclamações de clientes e alto número de produtos não conformes gerados no laminador, a empresa inseriu este projeto no planejamento estratégico para o ano de 2015.

A tabela a seguir evidencia as atividades conforme metodologia DMAIC.
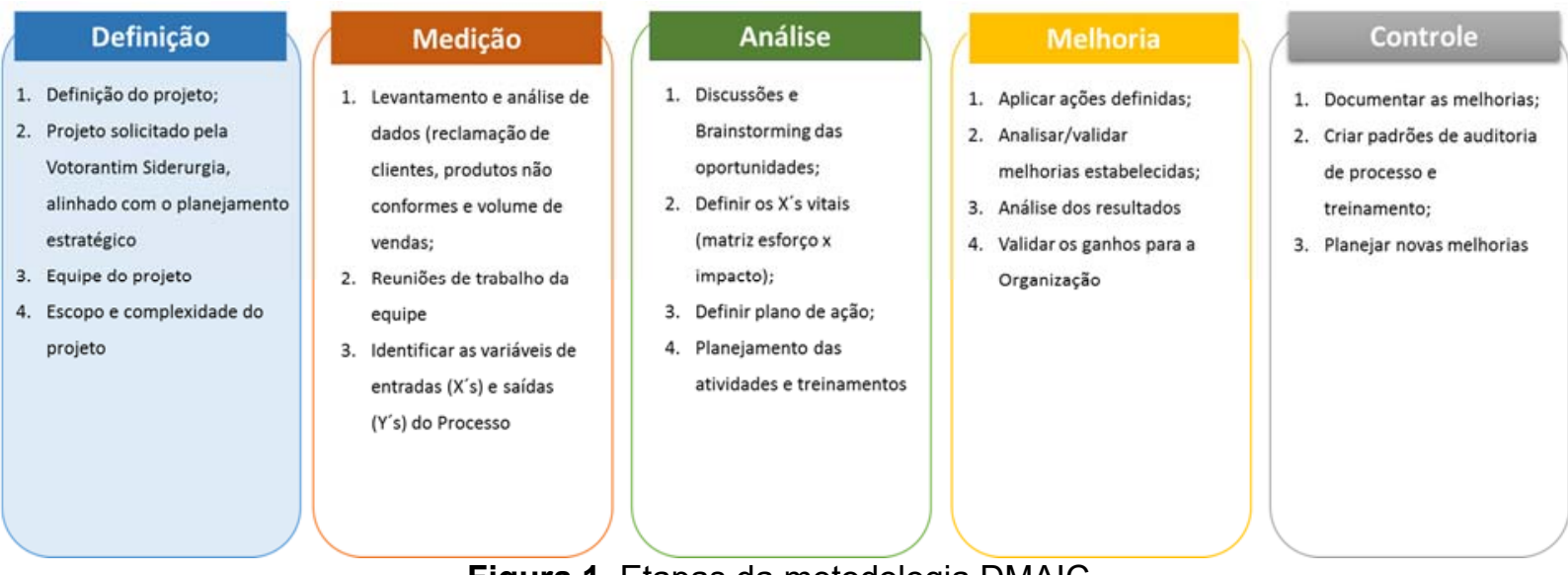

Figura 1. Etapas da metodologia DMAIC 
Na primeira etapa do projeto foi definida uma equipe multidisciplinar para atuar nas diferentes frentes de trabalho, envolvendo técnicos e engenheiros de processo e produto das áreas de laminação, oficina de cilindros e qualidade.

$\mathrm{Na}$ fase de análise de dados, realizamos um levantamento histórico das reclamações de clientes, número de produtos não conformes e redução no volume de vendas deste produto.

No ano de 2015 a Votorantim Siderurgia recebeu um total de 17 reclamações de clientes pelo motivo de dimensional fora do especificado nas Barras Redondas. Os principais defeitos dimensionais reclamados foram ovalização, largura e diâmetro.

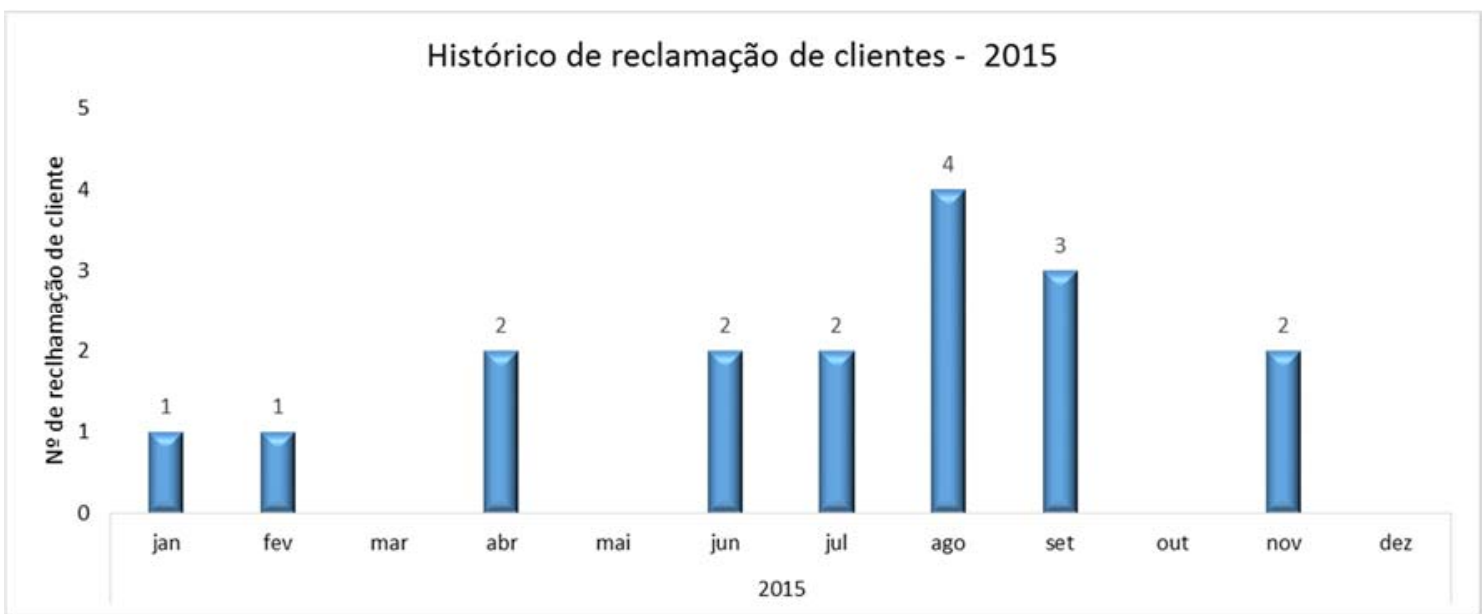

Figura 2. Histórico de reclamação de clientes 2015

$\mathrm{Na}$ figura a seguir podemos evidenciar duas reclamações de clientes por ovalização nas bitolas de 2.3/4" e 1.3/4". Os valores das ovalizações encontrados foram 4,3mm e $1,5 \mathrm{~mm}$ respectivamente.
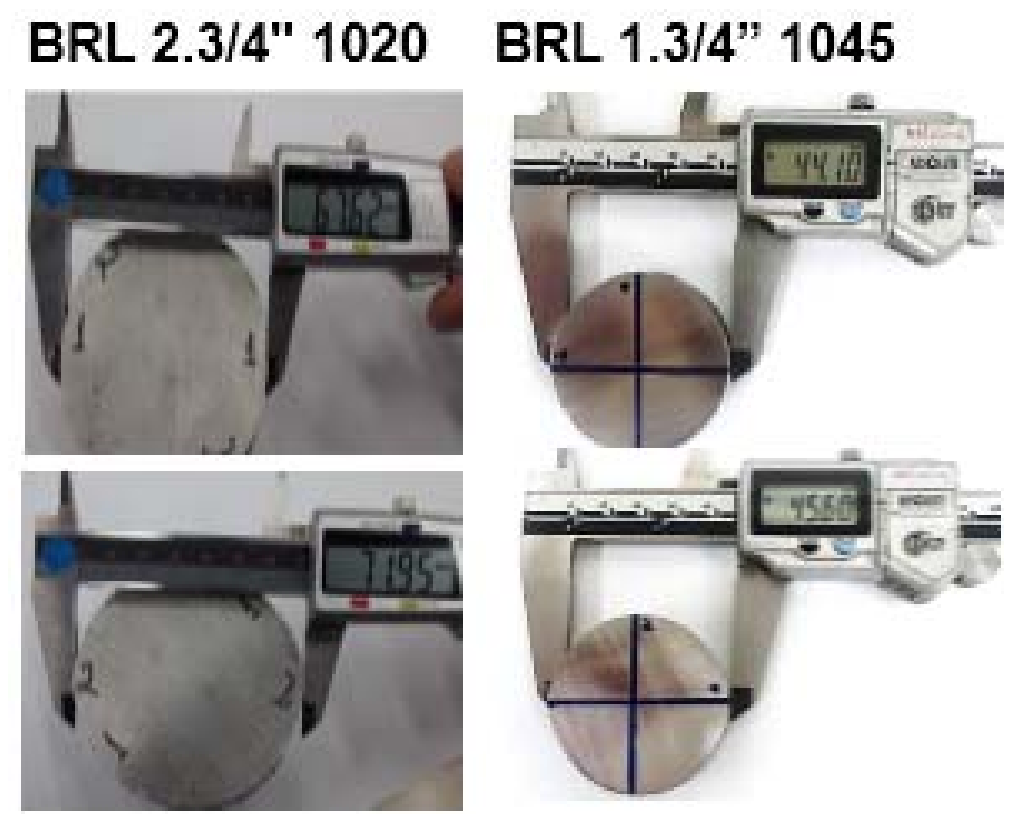

Figura 3. Reclamações procedentes de dimensional da barra redonda

O número de produtos não conformes apresentou um aumento de aproximadamente 50\% em 2015 quando comparado com o volume gerado no ano de 2014. 
Histórico geração de não conforme-BRL

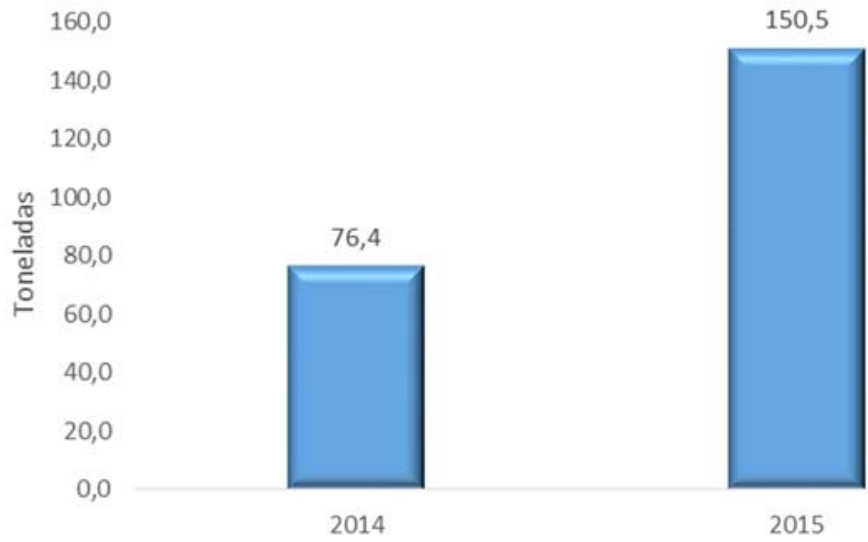

Figura 5. Histórico de não conforme nos anos de 2014 e 2015

Além disso, observa-se que devido à alta incidência de reclamações de clientes no ano de 2015 , houve uma redução de $30 \%$ no volume de vendas das barras redondas comparando com os anos de 2013 e 2014.

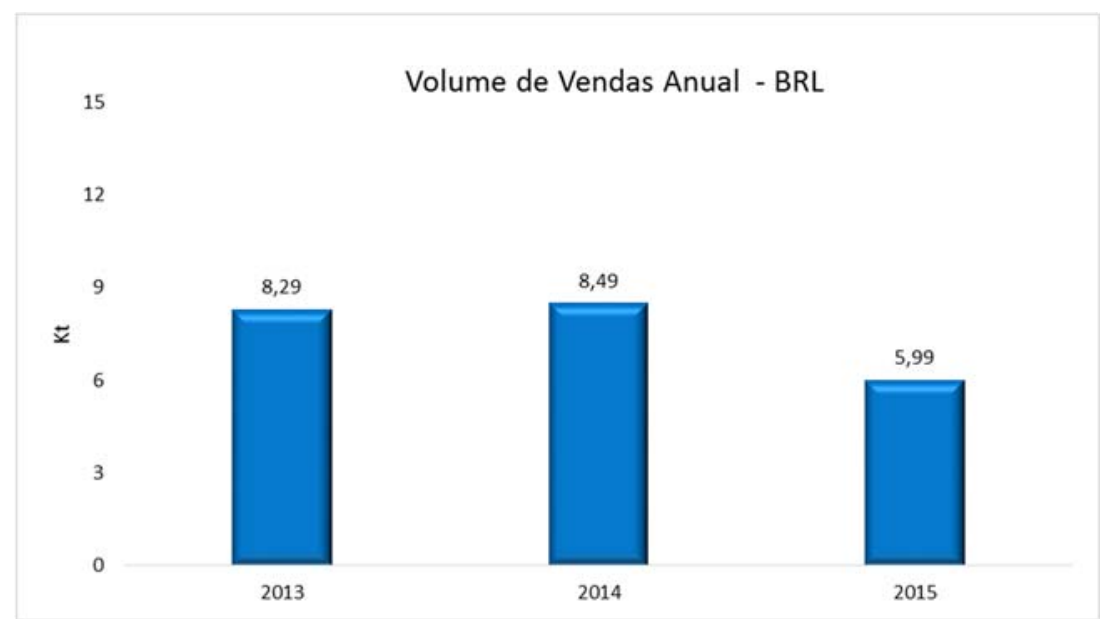

Figura 6. Volume de vendas de barras redondas nos últimos 3 anos.

Após a identificação dos principais problemas durante a laminação das barras redondas, a equipe iniciou as reuniões de brainstorming para listar as possíveis variáveis de processo com influência na ovalização do produto. 


\section{BRAINSTORMING}

\begin{tabular}{|c|l|}
\hline Número & \multicolumn{1}{|c|}{ Variável } \\
\hline$X_{1}$ & \% de redução entre passes \\
\hline$X_{2}$ & Formato do canal \\
\hline$X_{3}$ & Perfil do rolete \\
\hline$X_{4}$ & Guias inadequadas \\
\hline$X_{5}$ & Gaiolas com necessidade de reparo \\
\hline$X_{6}$ & Dificuldade no procedimento de queima de canal \\
\hline$X_{7}$ & Refrigeração dos cilindros \\
\hline$X_{8}$ & Regulagem de guia \\
\hline$X_{9}$ & Desgaste do estático \\
\hline$X_{10}$ & Desgaste dos rolos, calhas e chapas \\
\hline$X_{11}$ & Material dos rolos \\
\hline$X_{12}$ & Dificuldade de ajuste \\
\hline
\end{tabular}

Figura 7. Variáveis de processo

Através da matriz esforço $x$ impacto foram definidas as variáveis críticas para elaboração do plano de ação.

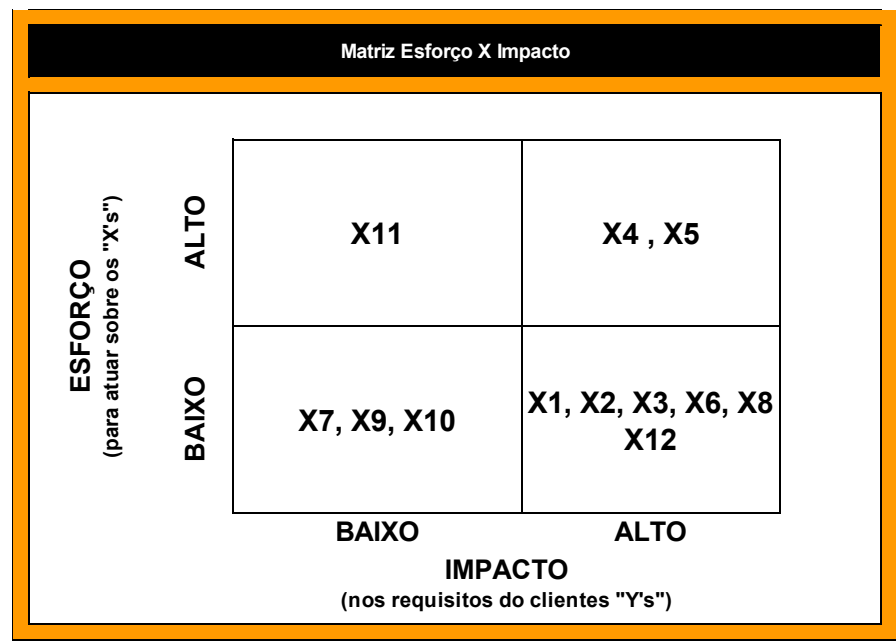

Figura 8. Matriz esforço x impacto

As variáveis definidas como críticas foram as que apresentaram maior impacto no processo de laminação e menor esforço:

$\mathrm{X}_{1}-\%$ de redução entre passes

$\mathrm{X}_{2}$ - Formato do canal

$\mathrm{X}_{3}-$ Perfil do rolete

$\mathrm{X}_{6}$ - Dificuldade no procedimento de queima de canal

$X_{8}-$ Regulagem de guia

$\mathrm{X}_{12}$ - Dificuldade de ajuste

Após identificação das variáveis críticas ao processo, evidenciamos os principais problemas relacionados às essas variáveis e definimos ações de melhorias.

$X_{1}$ - \% de redução entre passes e $X_{2}$ - Formato do canal:

Identificamos a necessidade de revisar a calibração devido à falta de preenchimento do canal preparador, o que levava à ovalização no produto e instabilidade de processo no acabador. Devido à esta falta de preenchimento, 
ocorria a possibilidade do material "tombar" no canal, gerando a ovalização no produto final.
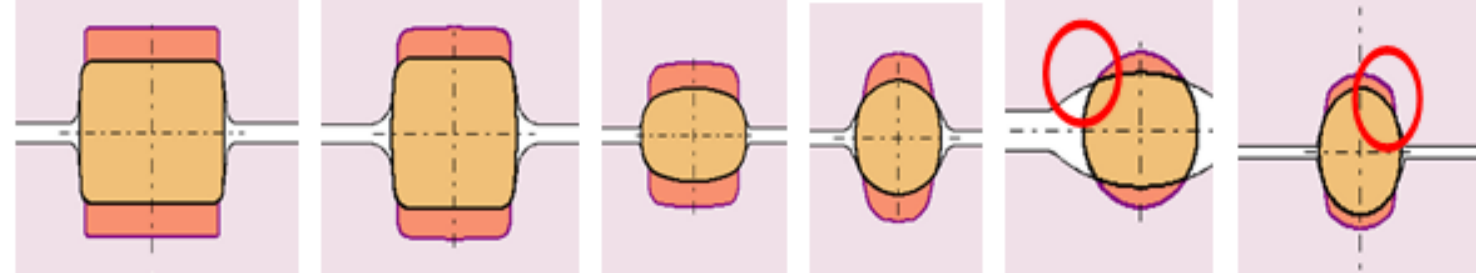

Figura 9. Configuração dos canais de laminação da BRL 2"

A figura 10 a seguir compara o preenchimento do canal antes da modificação da calibração e a proposta de alteração com maior preenchimento do canal, ou seja, maior área de contato do produto com canal.

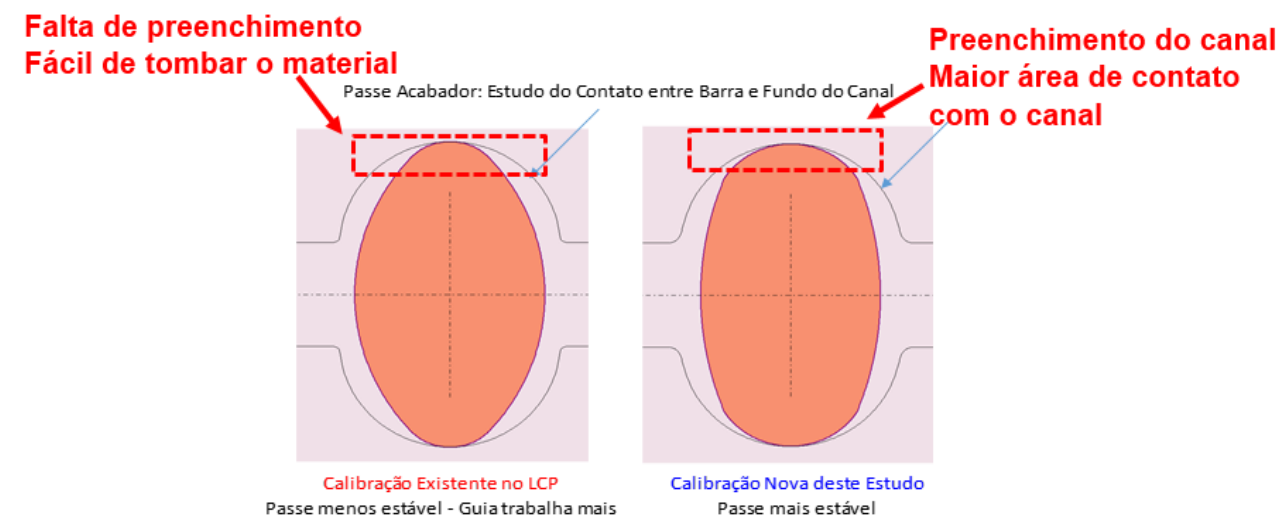

Figura 10. Comparação do canal antes x após alteração da calibração da BRL 2"

\section{$\mathrm{X}_{3}$ - Perfil do rolete:}

Verificamos a necessidade de adequar os roletes de acordo a nova calibração

\section{$\mathrm{X}_{6}$ - Dificuldade no procedimento de queima de canal:}

Durante a partida do laminador, ocorria algumas sucatas de linha devido à dificuldade de queima de canal, devido a isto elaboramos o procedimento de metalização sem lixar os canais para os canais das gaiolas acabadoras e recartilho para os demais canais

\section{$X_{8}$ - Regulagem de guia:}

Para eliminar as dificuldades durante a regulagem das guias, criamos um plano de manutenção e recuperação das guias, visando retirar as folgas dos braços, realizar reparo dos estáticos, para manter a medida de abertura padrão e confeccionar gabaritos, para auxiliar nos ajustes

\section{$X_{12}$ - Dificuldade de ajuste}

Outra ocorrência recorrente era a dificuldade de ajuste do material. Para mitigar essa ocorrência foram executas das seguintes ações: elaboração de um check list de partida do laminador e procedimento de retirada de amostras entre passes, confecção de gabaritos para verificar o ajuste dos axiais das gaiolas e treinamento on the job da equipe operacional e oficina de cilindros. 
Além das ações com foco nas variáveis críticas de processo com maior impacto, verificamos a necessidade de aturar em um segundo momento nas outras variáveis de processo, definidas durante o brainstorming:

\section{$\mathrm{X}_{4}$ - Guias inadequadas}

As guias antigas utilizadas nas gaiolas acabadoras eram de apenas 2 roletes, após análise da equipe, verificamos a necessidade de utilizar guias mais robustas, com isto alteramos de 2 para 4 roletes, que gerou maior estabilidade do produto no canal acabador.
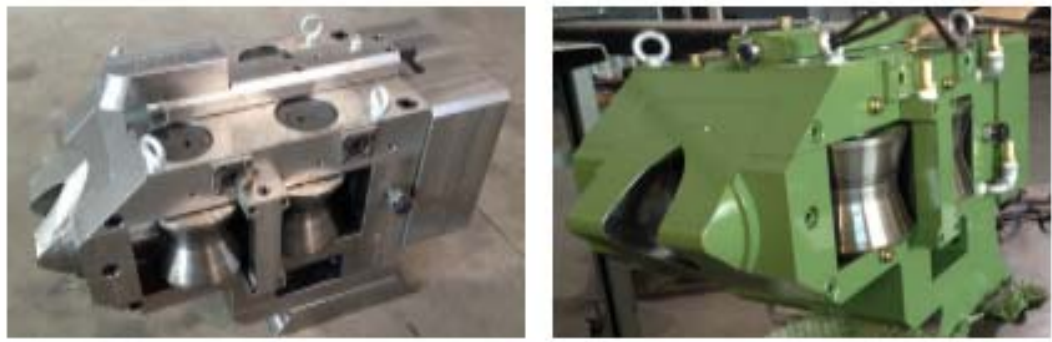

Figura 11. Guias 115 WFB -4 roletes

\section{$\mathrm{X}_{5}$ - Gaiolas com necessidade de reparo}

Devido à presença de folga nas gaiolas de laminação, foi elaborado um plano de recuperação de gaiolas;

\section{$\mathrm{X}_{10}$ - Desgaste dos rolos, calhas e chapas}

Para evitar a deteriorização dos rolos, calhas e chapas do laminador, foi elaborado um cronograma de atividades contendo as etapas de aquisição, reparo e manutenção destes itens.

Tabela 1. Cronograma de inspeção dos rolos, calhas e chapas do laminador

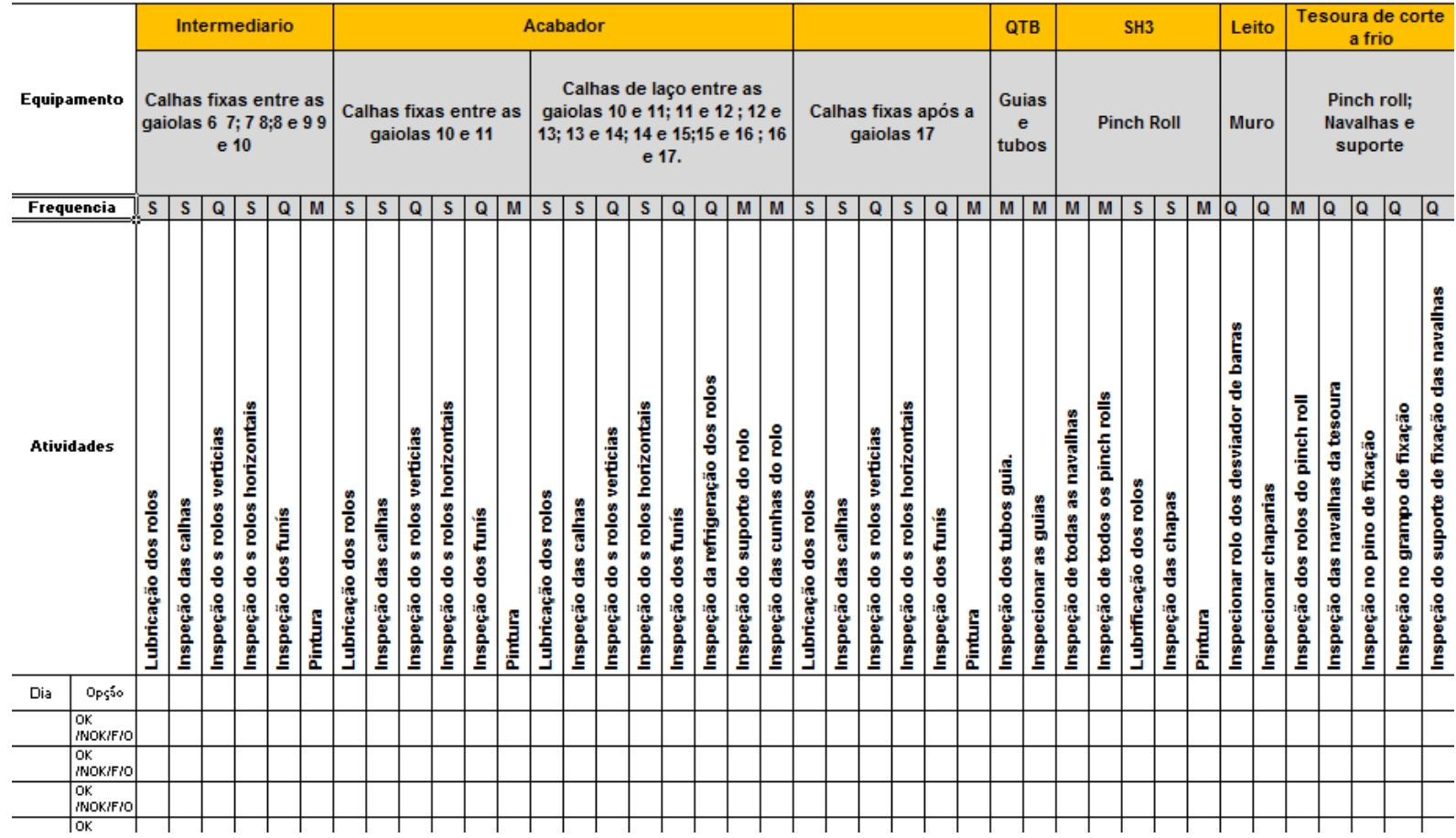


Antes

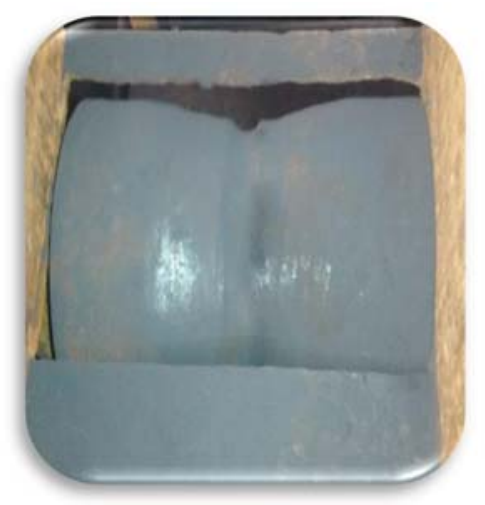

Depois

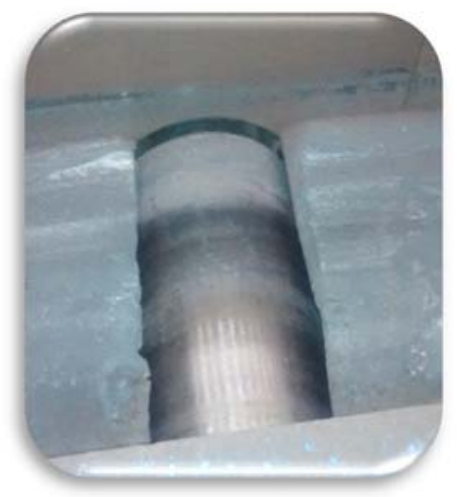

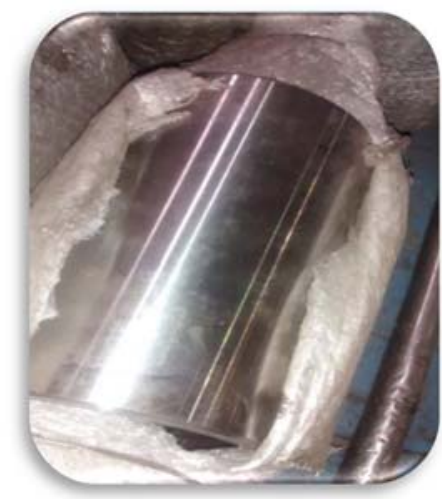

Figura 12. Rolos utilizados antes $x$ após a elaboração do cronograma

\section{RESULTADOS E DISCUSSÃO}

Após a conclusão do plano de ação, foi possível evidenciar algumas melhorias que auxiliaram na laminação deste produto, proporcionando maior estabilidade de processo.

Com as alterações realizadas na calibração do produto, foi possível evidenciar um maior preenchimento do canal acabador, o que possibilitou maior estabilidade da barra ao passar por este passe de laminação.

A seguir evidenciamos as alterações realizadas na calibração das bitolas 2.3/8" e 3".

\section{Bitola: 3"}

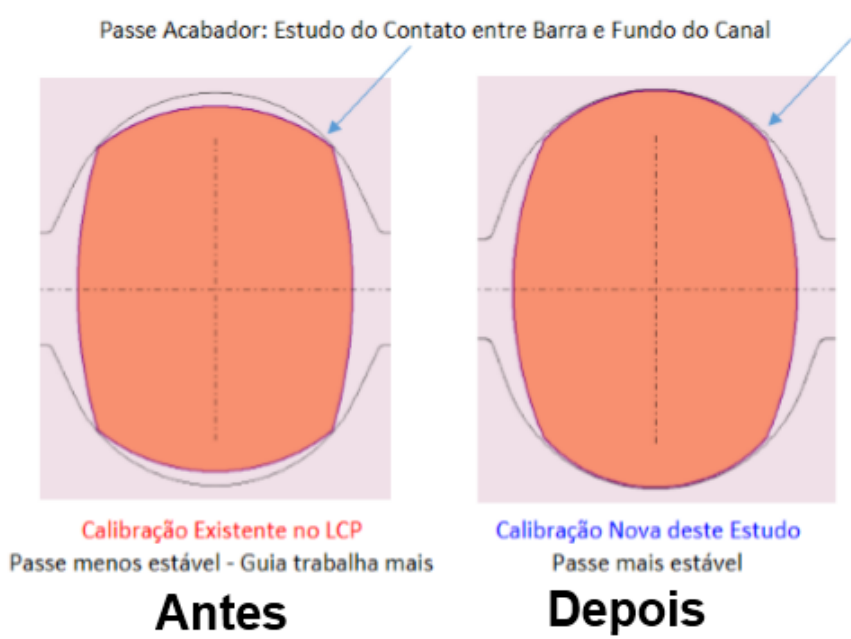

Figura 13. Alteração do passe acabador para a bitola de 3" 


\section{Bitola: 2.3/8"}

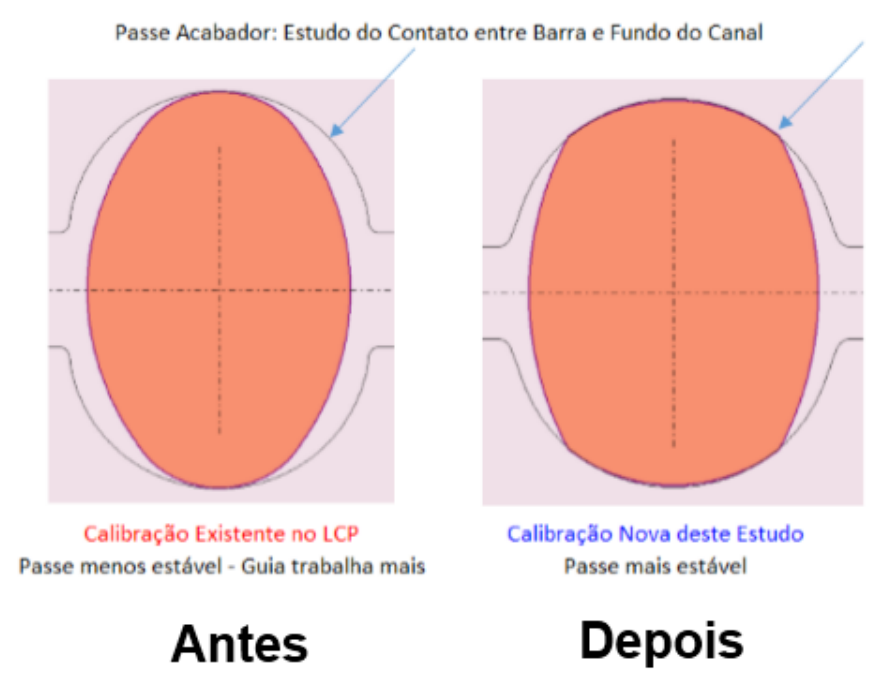

Figura 14. Alteração do passe acabador para a bitola de 2.3/8"

Após a conclusão do plano de ação, foi possível evidenciar uma redução de $36 \%$ em média na geração de produtos não conformes, nenhuma reclamação de cliente foi recebida, além da estabilidade do processo durante a laminação deste produto.

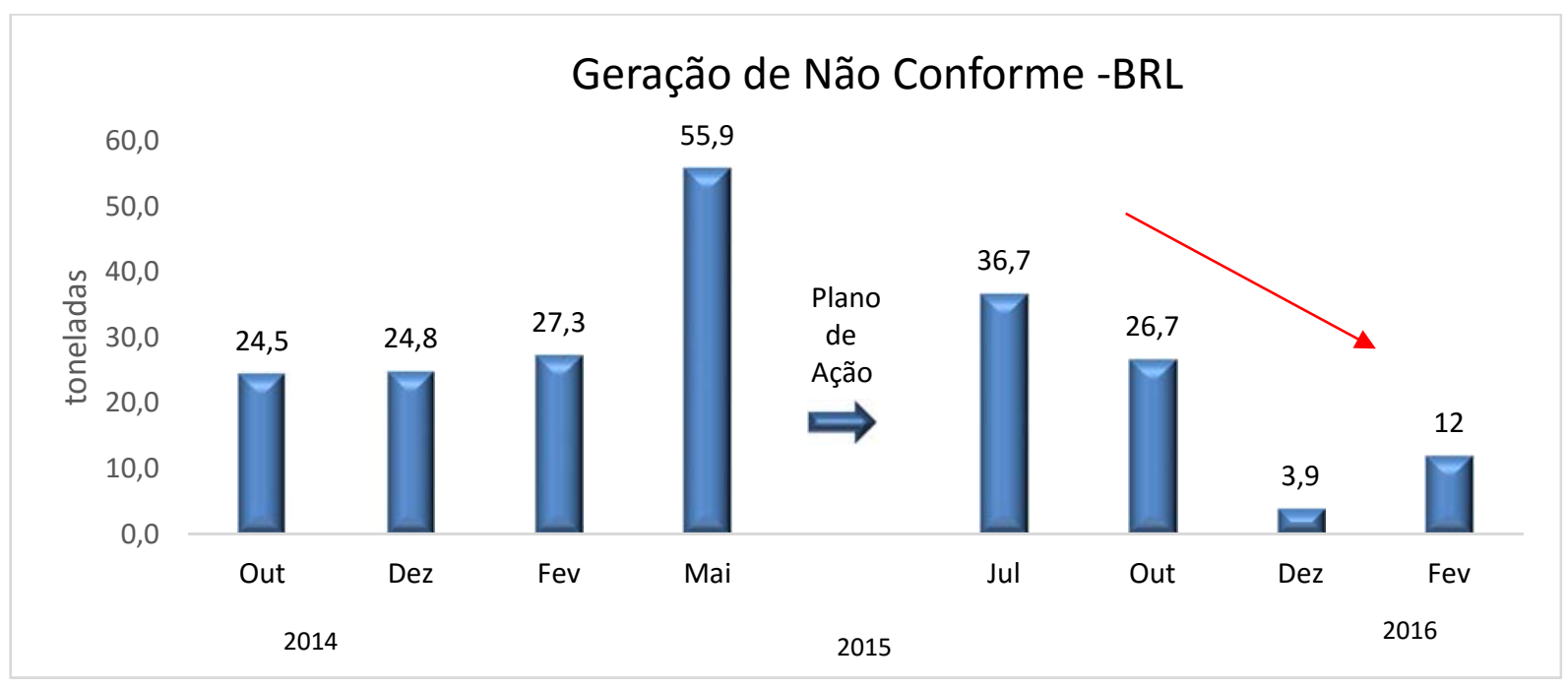

Figura 15. Histórico de não conforme

Devido aos problemas dimensionais recorrentes, muitos clientes reduziram o volume de barra redonda, o que ficou evidente quando comparado o volume total vendido em 2014 (8,49kt) e 2015 (5,99kt). O segundo semestre de 2015 foi um período de retomar a confiança dos clientes. Gradativamente, após confirmarem a melhoria no dimensional do produto, os clientes foram aumentando o seu volume. Esse fato pode ser evidenciado pelo gráfico abaixo, que mostra uma previsão $8,84 \mathrm{kt}$ para as vendas de barra redonda em 2016, volume no mesmo patamar de 2014. Apesar da crise econômica vivenciada pelas indústrias atualmente, é possível verificar o resultado desse projeto através dessa elevação no volume de barras redondas previsto para 2016. 
1200

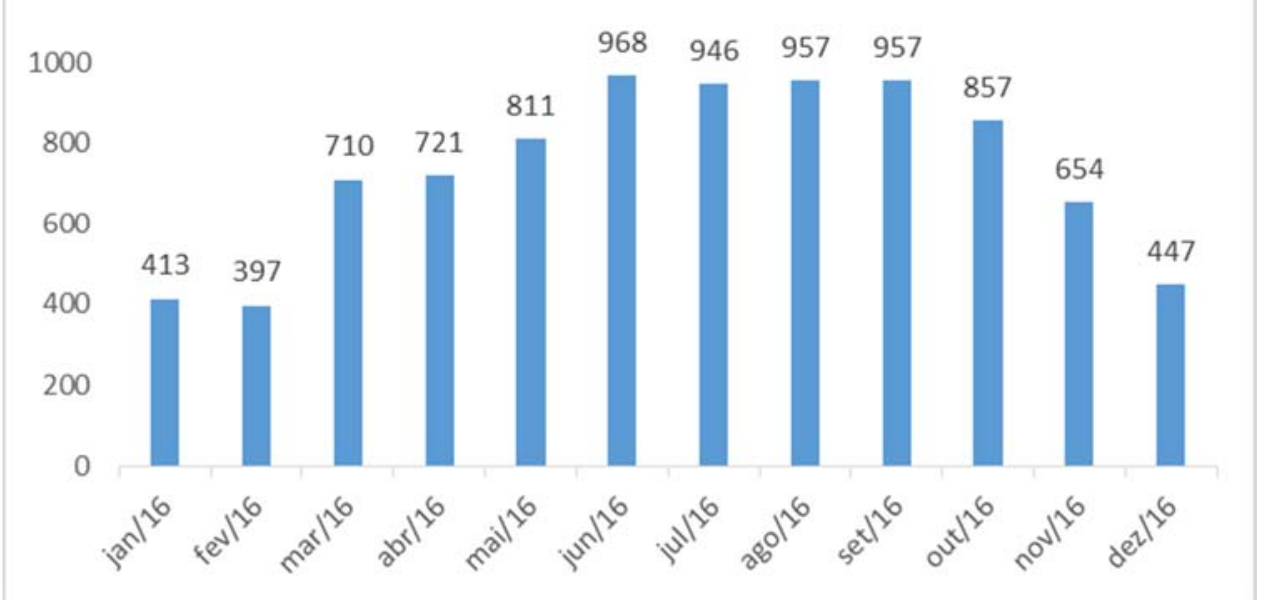

Figura 16. Volume previsto de venda de barra redonda em 2016.

\section{CONCLUSÃO}

A iniciativa da equipe deste projeto, de utilizar a metodologia DMAIC proporcionou o direcionamento das ações de melhorias para as variáveis críticas de processo. $\mathrm{O}$ objetivo inicial do trabalho foi alcançado, gerando maior estabilidade de processo durante a laminação das barras redondas, reduzindo significativamente o número de reclamações de clientes e geração de produtos não conformes.

É importante destacar que com estes resultados, houve um aumento da previsão de vendas destes produtos para o ano de 2016. O restabelecimento da confiança dos clientes proporcionou esse aumento. Atualmente existe uma tendência de queda no volume de vendas, considerando a crise econômica do país. A barra redonda é um produto de boa margem de contribuição, portanto esse projeto pode contribuir positivamente para os resultados da empresa em 2016.

\section{Agradecimentos}

- Aos supervisores de turno, colaboradores da operação e da oficina de cilindros;

- À gerência de laminação a quente

- À gerência de produto e processo

\section{REFERÊNCIAS}

1 Ernandes Marcos da Silveira Rizzo, Processos de Laminação de Produtos Longos de Aço, ABM, 2010'

2 NBR 13283, Barras de aço, laminadas a quente redondas, quadradas e sextavadas para uso geral - Dimensões, 1995. 